\title{
The Impact of Internet Finance on Commercial Banks and Countermeasures
}

\author{
Deyu Chen \\ Guangzhou College of Commerce
}

\begin{abstract}
The rapid development of internet finance has caused great impact on the current business model of commercial banks, therefore, how to transform the business model of commercial banks and meet the challenges from internet finance become an urgent issue that needs to be addressed facing all commercial banks. This paper describes the status quo of the development of internet finance, internet financial functions, and the risks faced by commercial banks, finally proposes corresponding countermeasures for the current situation of commercial banks.
\end{abstract}

Keywords-Internet finance; Commercial bank; Business model; Traditional finance

\section{INTRODUCTION}

Internet finance is an emerging field that combines the traditional financial industry with the spirit of the Internet. At present, financial innovation services such as mobile payment, online banking, mobile banking, and cloud finance are flourishing in China. With the booming development of technologies such as Internet cloud computing, innovations in the domestic Internet finance industry are on the rise. Among them, the development of Internet finance is particularly prominent. Alipay and Tianhong Fund cooperated to launch the Yuebao service. In essence, the balance treasure is equivalent to a kind of money fund. Compared with the traditional bank's current and fixed deposits, the balance treasure can more prominently highlight its advantages, and truly realize the survival and use of one yuan. It is convenient and quick to save. The balance treasure launched by Alipay is mainly invested in money market financial instruments with high security and stability, such as investment in government bonds and bank deposit certificates. Since the launch of this product, it has received a fiercely sought after market and has been dubbed the "Crown Management Artifact". After Yu Yuebao was widely accepted by the general public, other Internet companies also launched their own financial products, such as Baidu Baidu launched Baiyun Suning launched Suning wallet and other similar products. The current gathering of Internet finance stars has gradually formed a continuous development from the initial state to the present.

\section{Status Quo Of InTERnet FinANCIAL DEVElopMEnT}

The difference between internet finance and traditional finance lies not only in the different media used in financial services, but more importantly in the interpretation of the Internet's essence of "openness, equality, collaboration, and sharing" by financial participants. Internet finance brings new challenges to "deintermediation," "pan-finalization," and "allintelligence" to existing commercial banks. Its development is not only a useful complement to traditional finance, but also will promote China's financial efficiency. Deep changes in transaction structure and financial architecture. The popularization and development of Internet technology have changed the way people live, make friends, and trade, realizing the perfect combination of virtual communities and real life, and the transition between virtual finance and real finance. With the penetration of the Internet's spirit of "openness, equality, collaboration, and sharing" into the traditional financial industry, the operating model of traditional commercial banks will be affected.

Therefore, in the crucial period of China's financial industry reform, the study of the impact of Internet finance on traditional banking industry will not only help China's traditional banking industry to vigorously develop service function innovation, service channel innovation and platform model innovation in response to the impact and challenges of Internet finance. At the same time, it is also of great significance to promoting the continuous improvement and development of Internet finance itself.

\section{THE FunCTION OF INTERNET FINANCE}

\section{A. Financing function}

With the development of all aspects of the Internet and finance, Internet technology has penetrated into the financial sector. People have begun to realize this kind of convenient and fast emerging online financial services. The emergence of Internet finance has just made up for the traditional Chinese financial system, especially in small and medium micro. The short board in the field of financial services has injected new vitality into the development of China's real economy. Not only for enterprises, but also expand the ordinary residents of investment and wealth management channels, the release of investor enthusiasm for investment, help to play the role of private capital, and guide the informal finance to standardize. 


\section{B. Payment settlement function}

On the computer, even a few seconds of operation on the smart phone can complete the payment settlement and other services. Today, this mobile payment method is widely used in life due to its high efficiency and convenience. The rapid development of Internet finance business integrates traditional finance with the Internet to achieve full integration of scientific and technological advantages with the characteristics of financial products, providing customers with more convenient payment and settlement services. In the process, financial institutions provide more comprehensive and efficient service support., it is more efficient than direct application from customers.

\section{Investment and financing functions}

The rapid development of investment and wealth management APP has enabled the original financial management to enter ordinary people. Ali Ali's Alipay, for example, can use Alipay to directly purchase funds within the page, and can invest and manage funds through mobile phone operations at any time. Since 2015, along with the policy of interest rate cuts and RRR cuts that have been implemented repeatedly by the central bank, investment income is showing a slow decline. With the overall decline in market conditions, the return rate of internet financial platforms is also difficult to avoid. However, overall, the return on investment of internet finance is still higher than that of other wealth management products.

\section{IMPACT OF INTERNET FINANCE ON COMMERCIAL BANKS}

\section{A. Challenging traditional credit}

Big data, also known as huge data, refers to massive, high growth rates, and diversified information assets that require new processing models to have greater decision-making power, insight, and process optimization capabilities, in terms of type, production speed, and volume. The collection of data that exceeds the processing capabilities of traditional information technologies in many ways. With the development of the mobile Internet, the use of the Internet of Things and cloud computing, the rise of social media, and the popularity of smart phones, global data has grown explosively, bringing human society into a new "big data" era. As the "new oil of the future," big data has penetrated into all areas of social and economic life and has become an important production factor. According to the McKinsey \& Company report, the financial industry is the industry that can be the first to be affected by the era of big data.

\section{B. Diversion of bank deposits}

Since the yield is higher than the bank's savings rate over the same period, a variety of baby internet financial products have been diverted from the bank and a large amount of deposits, especially personal bank deposits, are being lost. According to the financial statistics released by the People's Bank of China, Renminbi deposits decreased by RMB 940.2 billion in January 2016, a deceleration of RMB 2.05 trillion year-on-year, excluding the holiday season of traditional Chinese New Year holiday. Another reason for the sharp reduction in deposits is various Internet finances. The product's powerful diversion capability. Alibaba rationally used the precipitation funds from e-commerce to launch the Yuebao business to many users, awakening these idle users who do not have investment plans or investment capabilities to become investors. Tencent did not lag behind. First, it launched a "Current Lifeline" product on the WeChat platform with China Assets, and then launched a financial wealth management platform based on the WeChat platform WeChat WealthLink, and the first batch of fund companies that had access to Huaxia Fund. With Yu Zhangbao's impressive gains, the partner Tianhong Fund has become a fund's first brother. According to the silver rate network statistics, benefiting from the skyrocketing scale of internet financial products, the size of money market funds has also grown rapidly. Money market funds have accounted for $41.7 \%$ of the public fund market, and have surpassed equity funds as the largest fund category in one fell swoop.

Whether it is Alibaba's Yu Bao or Tencent's WeChat Finance Platform, the main investment is short-term money market assets. Money market funds often have low returns and low risk, and their liquidity and safety are relatively high. It can be compared with bank savings. Therefore, these Internet financial products directly have a strong impact on the bank's savings deposit business.

\section{Extruding Intermediate Business}

In the field of daily credit consumption and microcredit loans, the authority of banks is gradually being transferred to other professional credit bureaus. Among the many Internet products, Alibaba is the closest to credit cards, behind which are the world's largest Taobao and Tmall, which allows Ali to directly control the shopping behavior of consumers and is closer to the financial services linked with credit cards. The user's needs, and the user's consumption data and financial transaction data accumulated through this process, will further become the basic data of the Ant Financial Service Credit System. The Jingdong IOU is similar to Alibaba, which is a credit card service provided by Jingdong Finance. The internal connection between JD.com and JD.com has become even closer. It has expanded more and more specific consumption scenarios to counter the advantages of Alibaba's e-commerce platform. The relatively single financial service product line of banks does not have the advantage of the user consumption scenario of the large e-commerce platform, and the products and resources that cannot be internally linked are at a disadvantage. 
Under the Internet finance model, Internet companies provide a financial search platform for both supply and demand of funds, and act as an intermediary for fund information. From the perspective of financing, the capital supply and demand sides use the search platform to find trading partners, and the subsequent financing transactions are completed by both parties themselves. From the perspective of payment, third-party payment platforms can provide settlement and payment services such as payment collection, automatic payment and transfer and remittance to customers, replacing traditional bank payment services. Internet finance will accelerate financial disintermediation and make the commercial bank's financial intermediary function marginalized.

\section{THE DEVELOPMENT OF COMMERCIAL BANKS}

\section{A. Accelerating cooperation with third-party payment platforms}

At present, the main source of revenue for domestic commercial banks still depends on the spread income generated by deposits and loans. The level of electronic development of commercial banks is still far below the requirements of modern banking. In this sense, cooperation with third-party payment platforms to promote the development of online banking services is not only a requirement for the development of the Internet and ecommerce, but also an inevitable choice for the development of modern banking.

With the changes in people's payment patterns and behavioral habits, commercial banks must focus on the development and promotion of quick payment models represented by mobile payments, improve payment efficiency, provide financial value-added services represented by credit and supply chain financing, and create new profit growth point Commercial banks should actively seek cooperation with third-party payment platforms and vigorously promote commercial banks' various businesses such as wealth management services, fund operations, and gold business through third-party payment platforms, absorb customer idle funds, and realize customer capital appreciation.

Commercial banks can also promote the construction of unique online malls. Although commercial banks have inherent advantages in terms of payment models, they are still inadequate in e-commerce. Therefore, commercial banks should build malls that meet their own characteristics based on their own corporate culture and customer needs.

\section{B. Strengthening risk control through big data}

Try big data sharing and implement the big data financial model, which is based on the collection of various data such as massive customer transactions. In order to predict customer behavior, we analyze and excavate customer transaction and consumption information to facilitate the provision of financial services to customers. All-round information enables financial institutions and financial service platforms to gain insight into marketing and risk control. Strengthen the analysis and application of big data. As the most important and basic financial service institution, banks also continuously accumulate various data of customer financial behavior in the process of providing financial services to customers. Through the information contained in these data, banks can build customer-related information. The database of behaviors, and through professional data analysis to tap the customer's transaction and consumption information, master the customer's consumption habits, and thus accurately predict customer behavior. At the same time, through the analysis of the transaction status of different types of customers, we can truly grasp the needs of customers and provide more systematic business support for the innovative marketing and risk control of products in order to truly maintain the core competitiveness of commercial banks.

\section{Emphasising on customer experience}

More thoughts should be given to banks by internet finance. Banks should make full use of the principle of big data sharing and timely use the Internet to perceive the needs of customers. The banks also vigorously expanded the ebanking business, made online banking a more comprehensive platform, improved loan business services, and organically integrated e-banking with commercial networks. Through data analysis and real testing, the service meets the customer's spending habits; the loan business is made Internet-based; and secondly, the process is simplified as far as possible without affecting risk control.

\section{Joining B2B Supply Chain Finance}

Although SMIC can provide enterprises with unsecured and unsecured pure credit loans, the amount of financing is not sufficient. For B2B industries that require large-scale financing, as well as large-sum commodity industries, the bank-based financial industry needs to be integrated into the B2B supply chain finance. Banks should seize the opportunity to collaborate with the platform to obtain quality customer and transaction data recommended by the platform. The combination of online and offline practice is of great significance to banks, customers, and platforms.

All in all, the scale of Internet finance is still unable to compete with traditional financial forces. Internet finance is currently developing rapidly and has injected new vitality into China's financial industry. It represents a new direction for the development of the financial industry. It will undoubtedly have a great impact on the traditional financial industry, but now the total amount of payment for China's Internet payment companies. The total amount of the total payment is very low, and it will not far hit the current financial system. Therefore, the outcome of the game between Internet finance and traditional financial forces is still very uncertain. Due to policy risks, there are also hidden concerns in this emerging industry. In addition, Internet finance also faces a series of issues including the establishment of Internet licensing mechanisms, the establishment of identity authentication mechanisms, privacy protection, the enhancement of computing capabilities, and the establishment of credit platforms. In summary, we can see that the future development of Internet finance is not smooth. 


\section{ACKNOWLEDGMENT}

Notes: This topic is the phase achievement of the electronic business construction project of Guangzhou Commercial University, a key discipline in Guangdong Province. Document number: Guangdong Provincial Department of Education Guangdong Education Research Letter [2017] Number 1; Project number: TSZDXK201601".

\section{REFERENCES}

[1] Gong Xiaolin. The Impact of Internet Financial Model on Traditional Banking Industry[J] Financial Practice.2013

[2] Li Jianchao. Analysis of Internet Finance [J]. Times Finance, 2014(11).

[3] Wu Xiulun. Research on the Impact of Internet Finance on Traditional Banking Industry: Taking YUN Bao as an Example [J]. Times Finance, 2014(12). 